The question now arises whether the brand of the serum employed played any active part in the causation of this partieularly intractable form of polyarthritis. I think there can be no question that polyarthritis may occur during the course of bacillary dysentery, quite in dependently of any serum treatment, but may it not be that some substance in the brand of satidysenteric serum employed, such as a large proportion of toxic proteins, can exert a deciding influence on the production of joint effasions? There would appear to be, from the figures at my disposal, some grounds for such a supposition; for amongst $m y$ series of cases a polyarthritis occurred in 8 out of 29 injected with a certain brand of serum (that is, 27 per cent.), whereas in 335 convalescent and slight bacillary cases admitted to hospitai during the same period, and who were not treated with serum of any kind, only one case of arthritis occurred.

In addition to this evidence, through the kindness of Lieut.-Colonel C. J. Martiu, C.M.G., D.S.O., F.R.S., I have been able to obtaiu his statistics from an Australian General Hospital for comparison with my figures. The Australian statistics show the remarkable fact that 358 cases, from nearly all of whose stools the specific bacillus was isolated, were treated with large intravenous injections $(100 \mathrm{c.cm}$. or more) of Lister Institute antidysenteric serum with apparently favourable results, and without the supervention of a single case of arthritis. Similarly, in 1910 I gave over one hundred consecutive intravenous injections of Lister Institute antidysenteric serum without the supervention of a single complication of this nature.

\section{Infrequent Complications.}

Iridocyclitis and parotitis, which have recently been noted.

The iridocyclitis occurred in two cases six weeks after the initial dysenteric attack; one patient suffered from arthritic symptoms, whilst tlue other did not.

Parotitis was observed in three cases presenting no obvious signs of oral sepsis. In one there was a unilateral and in the other two a uniform bilateral swelling of the parotid gland which appeared suddenly and disappeared almost as suddendy. In both cases the swelling of the parotid coincided with the development of the concomitant artluritis.

\section{Sommary.}

It is reasonable to suppose that there exists an idiopathic dysenteric arthritis due to the absorption of specific dysenteric toxins from the bowel wall and their excretion (as is known to be the case during the absorption of toxins of septic and gonorrhoeal origin) into the joint cavities.

In the same manner the arthritic symptoms occurring during the course of serum sickness may be justly regarded as representing an effort on the part of the organism to rid itself of toxins peculiar to horse serum; and it is possible that a particularly high percentage of these toxins, even when introduced in moderate doses into a subject already suffering from dysentery in which per se arthritis is not an infrequent complication, may not only determine the onset of the condition, bat also the amount of disintegration of the joint thus produced.

1 Hyoiene and Diseases of Wa rm Climates, 1893. 2 The Dysenteries, b. 382. 3 Lancet, November lst. 1919, pv. 775-778. Ibid., Dp. 778-780.

\section{INSTINCT AND HYSTERIA.}

BY

\section{T. CARRUTHEI:S, M.B., F.R.C.S.EdIN.,} MAJOR R.A M.C.

Tre springs of conduct are obscure and not to be discovered at a glance, but it seems likely that our actions can be traced back to a basis of psycho-physical dispositions, more or less modified by outside influences and by interaction between such dispositions themselves. The innate dispositions, when considered in their simplest manifestations, are known as the primary instincts. On analysis an instinct is found to consist of three elements-. the cognitive or afferent, the affective or central, and the conative or efferent. McDougall describes a number of primary instincts, to each of which he assigns a primary emotion, which is the affective element of the instinct.
He describes others in which the emotion, though doubtless present, has no name. From his list we select the following as having a bearing on our subject:

(a) The instinct of flight and the emotion of fear.

(b) The instinct of curiosity and the emotion of wonder.

(c) The instinct of pugnacity and the emotion of anger.

(d) The instincts of self-abasement or subjection, and self. assertion or display; of which the affective sides are the emotions of subjection and elation, or negative and positive self-feeling.

(e) The parental instinct and the tender emotion.

$(f)$ The sex instiuct.

When we watch the play of instincts we notice that their conative activity is clirected to the attainment of pleasure, the elimination of painful feeling, and to the good of the individual or species; in other words, that the conation arising in the activity of an instinct is of a teleological or purposive nature. But this is not the same as to say that it is a conscious endearour towards a foreseen end; for example, the salmon, surmounting the waterfall by a supreme effort, has not directly in view tho good of its progeny. And many a man who all his life has held strong political views, imagining them to be founded on the dictates of pure reason, would be offended if it could be shown that his opinions are founded (as is of ton the case) on his instinct of pugnacity and the emotion of anger against those who hold opposite views. The action of running arvay under the impulse of fear might seem to be a consciously direcied endeavour; but the other motor activities, such as rapidity of the heart's action and respiration, are equally part of the flight instinct, and are obvi isly not consciously directed.

Instinctive behaviour is sometimes extremely simple, at other times complicated to a high degree. The simpler forms are commonest among the lower animals, and the highest complications are found in man. As an example, the instinct of pugnacity when aroused may result in an attempt to hurt an opponent by a blow, or in the complex and long-lasting efforts involved in a lawsuit. An observer who was unacquainted with civilized man might find some difficulty in classifying under the same heading the conduct of the cock that flies at his enemy's head at sight, and that of the prosecutor in a lawsuit sitting for weeks in a court listening to speeches, conferring with counsel, and talking notes. A savage, also, whose notion of the sex instinct was limited to the sexusl act, would bo puzzled to account for the civilized young man writing verses "To Chloe, on finding lwer fan." But though man shows the highest degrees of complicated instinctive behariour, in animals also the conative aspect of an instinct may be exceedingly complex. This is seen in the case of bees, spiders, birds, etc., in whom the parental instinct is greatly modified asd complicated. Differences between the modifications of the instinctive behaviour of animals and man lie in the fact that the complicated conative disposition of animals is the same in different individuals and is transmitted unchanged to their descendants; whereas no two men act exactly in the same way under the influence of fear, anger, wc ler, elation, and the rest, and complications are not transmitted as such. Though we can observe instinctive behaviour modified and complicated almost out of all recognition in both man and animals, the factors producing these modifications are somewhat obscure. That the intelligence may play a large part in the case of man is seen in such an instinct as curiosity, which is the mainspring of scientific research; but how birds were moved to build nests by the parental instinct, or how certain species of rats, moved by their flight instinct, adopted an aquatic life, and why these complications of originally simple conations were transmitted to their offspring, we do not know.

In the study of the etiology of certain functional dis. orders it has seemed that some advantage might $\mathrm{kb}$ derived from considering the primary instincts. Astris well known, mutism, paraplegias, paraesthesias, blindness, deafness, amnesia, etc., are common during the strain of battle. All these are disorders which incapacitate a man from service and cause his removal from a dengerous area to hospital and safety; in this way they serve the instinct of flight, which, like other instincts, is teleological or pur. posive in its conative aspects. It is surely not more remarkable that the flight instinct should make a man paraplegic than that the parental instinct should cause a bird to build a nest: or that the sex instinct should lead 
Orlando to pin verses on to trees. At the first glance all these activities seem equally remote from the primitive, efferent function of the instinct; but they have in common the one fact that they adrance the purpose of the instinct. This does not necessarily imply conscious endeavour to a foreseen end. When such endeavour is present we may (apart from malingering) get the phenomenon of the selfinflicted wound, which is an example of the intelligence usurping the entire conative functions of the instinct of flight.

This parallelism of the activities of the reasoned and unreasoned conations, producing in each case the same result (namely, illness), is a point that seems interesting to note, and can be matched in the play of other instincts besides that of flight.

In the study of the most common functional or "hysterical " troubles outside military life the instincts of selfabasement and self-assertion should be recalled.

Self-abasement, with its emotion of negative self-feeling or subjection, is evolsed by failure in the primitive human occupations-war, love, reproduction-and by pain and fear. Its conative activity censists in crouching, cringing, or slinking attitudes of body, or (in the civilized) of mind. Its object seems to be the propitiation of a superior power or the eliciting of sympathy or pity; it is well seen in the whipped dog. An interesting human example was seen by the writer in the case of a Truil marker who, being accidentally shot on the range by a soldier, fell on his knees and salaamed repeatedly to the man who had shot him. One does not often witness the bodily exhibition of the instinct among civilized people, though the mental equivalent is very common. If the instinct of selfabasement is successful in gaining the sympathy or consideration which is its object, it is liable to change in a curious way into the instinct of self-display. If the cringing dog is given a few words of encouragement it immediately starts exaggerated gambols and friskiness, and becomes animated by impulses directly opposed to those that at first kept it cringing and shivering at its master's feet. The case of over-servile persons will readily occur to the mind as an instance of the same thing. in the mental sphere. The instinct of self-display or selfassertion is chiefly evoked by success in the primary human activities, such as war and sport, love and repro. duction. Its affective side, positive self-feeling or elation, is pleasurable; but its conative side, which consists simply in conduct known to boys as "showing off," does not seem to be of any great service to the individual or species. The point that stoould be noticed in both the instinct of self-display and self-abasement is the frequency with which they operate in close asseciation with the sex instinct. 'This perhaps explains the original purpose of self-display.

Returning to the etiology of "hysterical" manifestationso we find that the symoptoms (aphonia, monoplegia, analgesia, or what not) are commonly found to follow an incident such as an unfortunate love affair, the dis. covery of a disease of the reproductive system, or a terrifying and painful occurrence. Here we have those factors which evolre the instinct of self-abasementfailure.in love or reproduction, fear and pain. The goal of the instinct is to. elicit pity, sympathy, or attention from other people. In modern civilized life the best way to do this: is to be ill; for the primitive conative activities of crowching, wailing, rending of garments, putting dust on the heed, etc., no longer impress the public as of old, and may even excite ridicule. Aocordingly the patient exhibits symptoms that often go with organic disease, and can sometimes hardly be distinguished from the latter even by an expert. That such phenomena can be seen apart from any voluntary oriein, is shown by the fact that thesedrmptioms are very often of a lind that are not under voluntary control at all, such as excessive borborygmi, local vasomotor disturbances, spasm of the oesophegus, and the other visceral manifestations of hysteria. These activities of the instinct of self-abasement are often seen to awaken (when successful) the instinct of self-display and the manifestations of positive self-feeling, in the manwer alluded to above in the case of the dog. In other wonds, the patient, from being hambly miserabie, comes, under the influence of wondering and sympathetie friends, and porhaps of the zodous pirysician, to take a pride in lier symptoms and to derive undonbted gratification from showing them off and developing new ones. Henoe the value of isolation treatment.

As, when surveying the involuntary disorders arising under the instinct of flight, we saw in self-inflicted wounds a parallel phenomenon guided by the intelligence, so in the "hysterical" class we observe conditions such as dermatitis artefacta, apparent fasting, alleged anuria, etc., which are all instigated by purposive intelligent conation.

The scope of suggestion in the production of functional troubles has not, so far, been mentioned. Some authorities, notably Babinski, attach extreme importance to it. There is no doubt that it often determines the type of symptom that arises. For instance, a slight injury to a limb may be followed by a monoplegia. A difficulty in swallowing during painful emotion, especially when accompanied by weeping, may initiate the globus hystericus. But it is here suggested that as imitation and suggestion play such a very large part in the causation of normal conduct, wa should admit that they may have the same part in producing hysterical behaviour, witlout being the original causes of it.

In conclusion, how does the theory pat forward in the preceding observations agree with the Freudian hypothesis? The school of Freud appears to explain morbid functional disturbances by supposing that the natural conative activity of an instinct (always the sexual) is liable to repression by the cen:-ship of the moral nature or of education. The normal constion being thus in abejance, the energy of the affect is transferred to an abnormal conative disposition, and functional disease follows. In this connexion it is interesting to turn again to the animal world. There we find beetles which, instead of running away when trightened, sham death; and birds which, under the influence of the parental instinct, develop a functional paralysis of a wing. What in these cases is the censor that represses the normal conative activity of the instincts, and what determines the exceedingly useful conative disposition that shall become linked to the affect; and could such repression of the conation and transfer of affective energy be transmitted to offspring as intact dispositions? The difficulty of answering these questions has led to the hypothesis advanced in these notes.

\section{Summary.}

1. Men and animals alike are swajed by a purposive impulse in their furdamental activities, and this impulse, or teleological striving, can be studied in the conative aspect of the instincts. In many animals instinctive behaviour consists in quite simple reactions, but we also find animals, especially insects, in which the behaviour is extremely complicuted: We do not know in the least how this complexity of animal behaviour is produced, but there is reason to believe it is due to something different from human intelligence.

2. In man the complexity of his instinctive behaviour is due partly to intelligence and partly to the same cause that modifies the primitive responses of the animal.

3. It is here suggested that certain functional diseases often represent the modified conative activity of primary instincts-especially of flight, self-abasement and selfdisplay; and that "hysteria" is an example in man of the complications which conations, originally simple, are known to undergo in animals.

\section{THE USE OF X RAYS AS IMMUUNITY-RAIBING AGENTS BEFORE AND AFTER OPERATION FOR CANCER.} BY

FRANCIS HERNAMAN-JOHNGON, M.D.

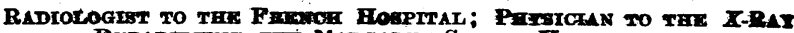

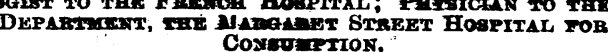

Post-ofkRATIVE $x$-ray treatment in breast cancer is generally regarded as right and proper, but it appencis necesenry to emphasize the fact that bofore operation a peculiaxty favourable opportanity is presented for teeatment by radiation. The lnife may be meass of disseminding sting cancer cells, but if, bofom the possibility of sach disseminatian eccurs we can bring abont either (1) the 